\title{
Representações sociais sobre a escola e seu impacto na constituição identitária de licenciandos em Química
}

\author{
Camila Lima Miranda ${ }^{1}$ \\ Vera Maria Nigro de Souza Placco ${ }^{2}$ \\ Daisy de Brito Rezende ${ }^{3}$
}

\begin{abstract}
RESUMO
O presente artigo apresenta resultados de uma pesquisa que objetivou, por meio do diálogo entre duas teorias: a das representações sociais e da identidade profissional de Claude Dubar, investigar as representações sociais (RS) sobre escola e sua influência na constituição da identidade profissional de licenciandos em Química egressos do sistema público de ensino. A partir da análise das entrevistas foi possível depreender que o compartilhar de RS acerca de um objeto não implica, necessariamente, em modos singulares de atuação. Os jovens, embora compartilhem uma $\mathrm{RS}$ do professor atuante nesse sistema de ensino como um profissional com uma formação deficiente, a qual conduz a uma atuação em sala de aula de baixa qualidade, agem de modo antagônico. Atuar como professor na rede pública de ensino pode implicar, para uns, assumir essa atribuição de baixa qualidade, enquanto, para outros, vincula-se à possibilidade de atuar de modo oposto àquele retratado nesta RS.
\end{abstract}

PALAVRAS-CHAVE: Escola. Representação Social. Identidade Docente.

\footnotetext{
${ }^{1}$ Doutora em Ensino de Ciências. Universidade Federal do Triângulo Mineiro, Uberaba, Minas Gerais, Brasil. https://orcid.org/0000-0002-3809-2882. camilamiranda.clm@gmail.com.

2 Doutora em Educação. Pontifícia Universidade Católica de São Paulo, São Paulo, São Paulo, Brasil. https://orcid.org/0000-0001-9515-2370.vera.placco@pucsp.br.

${ }^{3}$ Doutora em Química Orgânica. Universidade de São Paulo, São Paulo, São Paulo, Brasil. https://orcid.org/00000001-7715-0427.dbrezend@iq.usp.br.
} 
The social representations of school and the impact of a constitution of identity of students enrolled in a Chemistry teacher initial training course

\begin{abstract}
The present article presents results of a research, through the dialogue between two theories: the social representations theory, in the Serge Moscovici's perspective, and the one proposed by Claude Dubar refering to professional identity, to investigate the social representations (RS) about school and its influence in the constitution of the professional identity students of a Chemistry teacher initial training course, and came from public High School. From the analysis of the interviews show that the sharing of a SR regarding an social object does not necessarily implies in similar modes of action, these students share the SR that about the teachers acting in the governmental Basic Education system (compulsory school period; in Brazil it comprises primary school, lower secondary education, and high school period, totalizing 12 years) have a poor training to be professionals. Nevertheless, the subjects investigated in this work have different perspectives of action deriving from this shared RS. While some of them intend to work in the public basic schools, the other ones do not divise this possibility. For some individuals, to teach in the basic school public system might imply, to accept the low quality attribution while, for others, this action can favour an opposite intervention in relation to what is portrayed in this SR.
\end{abstract}

KEYWORDS: School. Social Representation. Professional Identity.

$* * *$

\title{
Introdução
}

A escola configura-se como um espaço em que são fomentadas as primeiras concepções sobre a docência e o contexto no qual essa docência é exercida. Há uma pluralidade de concepções sobre esse espaço físico e sua 
função na sociedade. Perspectivas de alguns autores (BOURDIEU; PASSERON, 2013; BOURDIEU, 2015; FREIRE, 1967; 2002; 2005; LIBÂNEO, 2012; YOUNG, 2007) convergem no que diz respeito à representação de que a escola historicamente traz a presença marcante do conhecimento das classes dominantes (BOURDIEU; PASSERON, 2013; BOURDIEU, 2015). As distinções se devem, então, à maneira como os estudiosos concebem a relação com esse conhecimento.

Na perspectiva de Pierre Bourdieu e Jean-Claude Passeron (2013), a partir da análise do ensino francês do final da década de sessenta, a escola configura-se como espaço de reprodução da marginalização das pessoas menos favorecidas. Nesse sentido, a escola pauta-se pelos ideais da classe dominante, que inclui, dentre outros aspectos, a perpetuação de sua linguagem, de modo que os que não a dominam, embora não conscientemente, distanciam-se cada vez mais desse ambiente, atribuindo-se uma possível deficiência, ou ainda,

a instituição escolar tende a ser considerada cada vez mais, tanto pelas famílias quanto pelos próprios alunos, como um engodo, fonte de uma imensa decepção coletiva: essa espécie de terra prometida, semelhante ao horizonte, que recua na medida em que se avança em sua direção (BOURDIEU, 2015, p. 248).

$\mathrm{Na}$ visão do sociólogo francês, as pessoas têm acesso desigual à cultura, detendo diferentes capitais culturais . Esse acesso é facilitado ou dificultado conforme a origem familiar (BOURDIEU; PASSERON, 2013; BOURDIEU, 2015). Os resultados escolares seriam moldados, então, pela distância entre a cultura escolar e a cultura familiar do aluno. Assim, na visão do autor, a escola legitima as desigualdades sociais. Essa legitimação se efetiva quando a escola trata como inatas algumas características que são desenvolvidas em função da cultura da família na qual a criança está inserida, de maneira que determina a eliminação contínua de crianças desfavorecidas culturalmente (em geral, as desfavorecidas economicamente). 
Paulo Freire (1967; 2002; 2005), em caminho distinto ao percorrido por Bourdieu, mais do que propor um modelo de como a escola trata as relações de ensino e aprendizado, deixou-nos um legado quanto a possibilidades mais efetivas dessa instituição abordar essa questão, contribuindo de forma muito significativa para a reflexão sobre como se construir uma Educação menos excludente. Priorizando a aquisição de conhecimento a partir da realidade objetiva dos sujeitos da aprendizagem, criticou o que denominou de educação bancária, uma visão epistemológica que concebe ser o conhecimento transferível do professor para o aluno, por explanação e mecanização. Intrinsecamente ligada a esse pressuposto está a concepção de passividade requerida do estudante: nesse modelo, não há espaço para os saberes dos educandos.

Para Paulo Freire, a Educação deveria ser pautada no diálogo, nomeada como pedagogia dialógica ou libertadora, desenvolvendo no educando uma postura ativa na construção de seu conhecimento, assim como possibilitando a construção de uma postura conscientemente crítica diante de seus problemas, em um compromisso com a transformação e inserção crítica em seu meio social (FREIRE, 1967; 2002; 2005). O autor defendia, então, que ao professor caberia a tarefa de orientar e dirigir o processo educativo.

Compartilhando uma mesma visão de Educação como possibilidade para a transformação, porém sob a égide da chamada pedagogia crítico social dos conteúdos, José Carlos Libâneo (2012) vislumbra a escola enquanto espaço para o desenvolvimento de uma consciência crítica, com vistas à transformação da sociedade. As atividades desenvolvidas nesse espaço deveriam contribuir para desenvolver as capacidades intelectuais dos estudantes, incluindo a percepção dessa necessidade de transformação, por meio do acesso aos conhecimentos. Por meio de suas obras, sob uma vertente histórico-cultural, Libâneo demonstra-se defensor de uma escola pública de qualidade. A importância da educação pública no País é incontestável, uma vez que ela desempenha, dentre outros, um papel significativo no processo 
de inclusão social, especialmente por, em tese, ser acessível a todos os sujeitos, capaz de promover a igualdade de direitos. Nesse sentido, Bourdieu (2015) diz que

com efeito, para que sejam favorecidos os mais favorecidos e desfavorecidos os mais desfavorecidos, é necessário e suficiente que a escola ignore, no âmbito dos conteúdos do ensino que transmite, dos métodos e técnicas de transmissão e dos critérios de avaliação, as desigualdades culturais entre as crianças das diferentes classes sociais. Em outras palavras, tratando todos os educandos, por mais desiguais que sejam eles de fato, como iguais em direitos e deveres, o sistema escolar é levado a dar a sua sanção às desigualdades iniciais diante da cultura (p. 59).

Igualdade deve significar, desse modo, atentar às diferenças e não ignorá-las. Com as devidas proporções, seja diagnosticando ou ressaltando que essas práticas devem ser combatidas, os autores supracitados concordam que oferecer as mesmas condições não basta para garantir uma Educação igualitária para a população.

Alguns autores (LIBÂNEO; OLIVEIRA; TOSCHI, 2012; MENDONÇA, 2011; YOUNG, 2007) defendem que, embora a escola não seja o único ou mais eficiente meio de socialização dos conhecimentos, não estamos diante de um processo de desescolarização da sociedade. De modo que, a nosso ver, ainda é possível vislumbrar a escola enquanto um dos lócus privilegiados para a socialização dos conhecimentos acumulados ao longo dos anos.

Assim, neste artigo relata-se parte de uma investigação que estruturou-se em torno do diálogo entre duas teorias: a das representações sociais (TRS; MOSCOVICI, 2001; 2012; 2013) e da identidade profissional de Claude Dubar (1992; 2005; 2009), com o objetivo de investigar as representações sociais (RS) sobre escola e sua influência na constituição da identidade profissional de licenciandos em Química (MIRANDA, 2018). 
Dada a pluralidade associada a esse espaço social, priorizamos a escola no âmbito público. Esse recorte é justificado ao se refletir sobre a importância da escolarização no âmbito público para a democratização dos conhecimentos para uma expressiva parcela da população. Dados do censo escolar de 2014, mostram que são 1.875.345 os alunos do ensino regular, que inclui o ensino infantil ao médio, sem incluir a modalidade de Educação de Jovens e Adultos (EJA), público da cidade de São Paulo, o que representa $83,2 \%$ do total de estudantes da cidade.

Além desse aspecto relevante, a universidade, em que os licenciandos investigados estudam, por meio de seu projeto pedagógico, declara que a formação dos sujeitos ali inseridos tem como foco a escola pública.

\section{Referencial teórico}

A Teoria das representações sociais (TRS) traz a concepção de representações, na qual a representação de um objeto não é um mero processo de reprodução e sim, a reinvenção do objeto. Nas palavras de Moscovici, "representando-se uma coisa ou uma noção, não produzimos unicamente nossas próprias ideias e imagens: criamos e transmitimos um produto progressivamente elaborado em inúmeros lugares, segundo regras variadas" (2001, p. 63).

Construídas a partir da comunicação entre os sujeitos, por sua natureza, não podem ser criadas por um indivíduo isoladamente, mas apresentam um caráter social de construção, e, como resultado, guiam os indivíduos em suas práxis diárias. Com a construção da representação social, torna-se possível "interpretar e conceber aspectos da realidade para agir em relação a eles, uma vez que a representação toma o lugar do objeto social a que se refere e transforma-se em realidade para os atores sociais" (WACHELKE; CAMARGO, 2007, p. 381). Portanto, a realidade construída por um grupo possivelmente irá diferir da construída por outro distinto e de 
seus respectivos comportamentos, tendo em vista que os "comportamentos dos sujeitos ou dos grupos não são determinados pelas características objetivas da situação, mas pela representação desta situação" (ABRIC, 2001, p. 156).

Por sua vez, para Dubar (1992, 2005, 2009), a construção da identidade se faz na articulação entre atos de atribuição e atos de pertencimento. Os primeiros se referem ao olhar do outro, uma identidade conferida aos sujeitos pelas pessoas que interagem diretamente com eles e pelas instituições; em outras palavras, é a identidade para o outro ou, ainda, uma identidade virtual. Complementarmente, os atos de pertencimento configuram-se como a identificação ou a recusa à identidade atribuída por outrem, podendo ser compreendidos como identidade para si ou identidade real. Essas considerações não se resumem a uma mera rotulagem: a atribuição de identidades apresenta aos sujeitos categorizações possíveis, o que pode resultar em sentimentos de exclusão ou de participação em grupos sociais, configurando-se como aceitação ou rejeição dos valores e significados inerentes às atribuições e consequentes incorporações.

Estar em relação é condição primordial para a constituição de identidades e de representações sociais. A identidade estudada através de uma perspectiva sociológica, tal qual proposto por Dubar, se concretiza, então, em uma tentativa de compreender "as identidades e suas eventuais cisões como produtos de uma tensão ou de uma contradição interna ao próprio mundo social” (DUBAR, 2005, p. 137).

Esse processo de reconstrução identitária é sempre mediado pela chamada negociação identitária, relacionada com a qualidade das relações com o outro, um movimento instituído pela negociação entre os interesses e valores pessoais e o contexto, sendo considerado por Dubar como um momento de tensão entre os atos de atribuição e pertença que constituem o sujeito, em que será posta em discussão a imagem dele como vista pelo outro (identidade para o outro) e a imagem que ele deseja apresentar (identidade 
para si), o que irá desencadear outro processo de construção, desconstrução e reconstrução de sua forma identitária.

Em termos identitários, é importante considerar o duplo papel das RS. No núcleo figurativo dessas representações, constam aspectos que se constituem atribuições para os sujeitos que desejam fazer parte dos grupos sociais que lhes atribuem tais RS; ao mesmo tempo, há uma negociação entre essas representações e aquilo que o indivíduo vai assumir ou não como pertença. Assim, a representação social apresenta duplo papel: se constitui atribuição de um lado e pertença de outro, tendo em vista que as representações sociais se constituem, com frequência, pertenças dos sujeitos (MIRANDA, 2018).

\section{Percurso Metodológico}

Os sujeitos que tiveram sua constituição identitária investigada são quatro estudantes do curso noturno de Licenciatura em Química de uma universidade pública paulista, egressos do sistema público de ensino. (MIRANDA, 2018). Visando garantir o anonimato dos entrevistados, foram atribuídos nomes distintos dos verdadeiros. Assim, são discutidas as representações de Laura, Simone, Tarsila e Guilherme.

$\mathrm{Na}$ tentativa de estreitar o diálogo com os licenciandos, possibilitando compreender melhor sua constituição identitária e a influência das representações neste processo, buscamos um instrumento que permitisse ao sujeito narrar os aspectos de sua trajetória pessoal e escolar que considerasse importantes, com liberdade e sem interrupções. Por isso, optouse pela utilização da entrevista. Mais especificamente, em nossa investigação, optamos pela utilização de entrevistas semi-estruturadas. Nessa técnica, embora exista um roteiro prévio de questões, podem ser propostas outras questões à medida que as informações vão sendo fornecidas pelo entrevistado (LÜDKE; ANDRÉ, 1986). As questões propostas neste 
instrumento estruturam-se em três eixos: trajetória na escola básica; trajetória na Licenciatura e representação de escola e de professor. Também, procurou-se questionar os licenciandos, sempre que pertinente, quanto à representação dos outros sobre suas escolhas e sua respectiva influência em sua própria representação.

Neste estudo, as técnicas de análise foram inspiradas na Análise de Conteúdo proposta por Bardin (1977), em que se busca "o realçar de um sentido que se encontra em segundo plano" (p. 41). Em outros termos, por meio desta análise, buscamos situar as informações obtidas pelas entrevistas em um contexto de representações sociais, atribuições e pertenças.

Dessa maneira, após a leitura da transcrição das entrevistas, emergiram as impressões iniciais que conduziram às demais etapas de análise dos dados, sob a luz dos referenciais teóricos eleitos, as representações sociais e a identidade profissional. Neste processo analítico, objetivamos evidenciar as

"palavras identitárias", as categorias pertinentes da experiência em cada uma das esferas de sua existência que o sujeito decide abordar. Pode-se, então, compreender como o sujeito construiu "mundos" que têm um sentido para ele e no seio dos quais podem se situar: mundos profissionais, culturais, religiosos, políticos, etc. [...]. classificar, não pessoas como sujeitos singulares, mas tipos de categorias e de argumentações, "ordens categoriais" e "universos de crenças", formas de linguagem que podem ser reagrupadas em classes e interpretadas como formas identitárias. A sociologia compreensiva e analítica procede por "tipificação" de discursos, de formas linguísticas, em campos determinados da atividade, mas o que é típico são as formas (discursivas, linguísticas, simbólicas) e não os sujeitos (DUBAR, 2009, p. 242).

Assim, conforme enfatizado por Claude Dubar (2009), não são os sujeitos investigados que estão sendo categorizados, mas sim as formas 
vislumbradas em seus discursos, não se objetivando reduzir os sujeitos a essa categorização. Nas palavras de Dubar (2009, p. 242) "cada pessoa não pode ser reduzida a uma posição em uma classificação, seja ela qual for: por definição, ela pode sempre mudar, modificar-se a si própria (com a ajuda de um terceiro), evoluir, converter-se, etc". Compreendemos, desse modo, a amplitude dos sujeitos em comparação à categorização da presente análise.

Tendo em vista nosso interesse no estudo da constituição identitária, dedicamos, ainda, especial atenção à análise dos processos de atribuição e pertença, os eixos fundamentais dessa constituição. Esse primeiro processo se constitui no modo como se interpreta aquilo que se acredita que os outros esperam, não sendo, necessariamente, o que o outro realmente espera do sujeito. Pode ser comparado a um filtro interpretativo e será essa interpretação que exercerá influência sobre o sujeito. Assim, é possível, a partir da narrativa dos sujeitos, ao relatarem os processos de suas constituições como docentes e futuros docentes, identificar as atribuições idealizadas - as quais podem ou não se tornar pertenças desses sujeitos. A fonte de dados para a análise dessa atribuição foi o discurso dos entrevistados.

Assim, seguimos pela análise de algumas representações que se destacaram nos discursos dos licenciandos, nos possibilitando dividir esta análise segundo as marcas dessas representações e, ainda, evidenciar a influência destas representações nos movimentos identitários vivenciados pelos estudantes. Nesse percurso analítico, elementos foram aproximados ou destacados, permitindo a organização dos dados em três categorias: (i) Atribuições dos "outros significativos" e "outros generalizados" (MIRANDA; PLACCO, REZENDE, 2018); (ii) Representações sociais sobre ser professor e constituição identitária (MIRANDA; PLACCO, REZENDE, 2019); e (iii) Representações sociais sobre a escola e constituição identitária. Esta última será alvo de discussão no presente artigo. 


\section{Resultados e Discussão}

A reflexão sobre a Escola recai em seu papel social, em representações sobre o aluno e, ainda, sobre o professor. Assim, apresentamos esta análise a partir de considerações sobre como estas e outras representações, as quais se interligam, se atrelam à representação social destes jovens sobre a escola e trazem impactos para a constituição identitária dos sujeitos participantes deste estudo.

No que se refere à escolarização, as experiências vividas como estudantes, antes e após o ingresso na Licenciatura, influenciam na construção de concepções sobre o exercício da atividade docente. Assim, da descrição de suas escolarizações, ecoaram alguns indícios que nos permitem tecer algumas considerações sobre suas representações e consequentes impactos em sua constituição identitária.

Vislumbrar a possibilidade do espaço escolar para além dos conhecimentos escolares tradicionais foi um anseio recorrente entre os entrevistados, como bem exemplificam as palavras de Simone: "que ela [a escola] tenha esse processo de reflexão sobre quem eu sou, onde eu estou e não [seja] apenas um ciclo, em que eu sou obrigada a ir para a escola. Você tem que enxergar o porquê daquilo". Para os jovens entrevistados, os estudantes precisam ser sensibilizados quanto aos porquês de estarem no ambiente escolar, algo dissociado da obrigação legal de frequentar a escola.

Esta percepção dos jovens sobre os processos a serem promovidos no ambiente escolar se aproxima da literatura (CANDAU, 2012, p. 247), em que se sugere que cada estudante "possa ser sujeito de sua vida e ator social", o que implica na promoção de práticas que os façam assim se reconhecerem. Essa compreensão um pouco mais ampla da escola também se aproxima de alguns dos pressupostos enunciados por Paulo Freire (1967; 2002; 2005), os quais se alicerçam na compreensão da Educação como

um processo humano; portanto, ela é fundamentada na transmissão ou na geração de valores [...] sua proposta é 
essencialmente uma pedagogia humanística voltada para as condições humanas, que deve considerar o mundo no qual homens e mulheres estão inseridos (SANTOS, 2008, p. 114).

Nesse sentido, percebe-se, na representação dos jovens entrevistados sobre escola, uma preocupação em buscar tornar audíveis as vozes dos estudantes, a qual se manifestaria na explicitação e na negociação da intencionalidade das práticas desenvolvidas no ambiente escolar.

Por sua vez, ao retratarem especificamente a escola pública, na fala dos jovens entrevistados, transparece a representação de que ensino público, no que se refere à Educação Básica, seja sinônimo de baixa qualidade. Assim, a escola pública suscita representações relacionadas à ausência de excelência no trabalho desenvolvido nesse espaço formativo.

A familiaridade com a escola básica pública relaciona-se com a própria trajetória biográfica dos entrevistados, tendo em vista que suas escolarizações se deram, quase que exclusivamente, em escolas públicas. Assim, a associação do público com o ruim deve-se a suas próprias vivências, assim como a um contexto social e midiático que costumeiramente desqualifica o ensino desenvolvido nesse âmbito e o professor que atua nele. Há de se considerar que esse discurso do fracasso da escola pública é uma representação social tão forte que se assemelha a uma crença.

Esse é um possível reflexo da política neoliberal que se impõe quase hegemonicamente hoje no País, sendo a desqualificação da rede escolar pública, em todos seus aspectos, um dos principais impactos dessa orientação política na Educação, como já apontado por Libâneo, Oliveira e Toschi (2012), que mostram ser o cerne da política neoliberal advogar a "incapacidade administrativa e financeira de o Estado gerir o bem comum" (p. 114).

Essa associação do público ao bom ou ruim se manifesta, especialmente, no relato de Laura sobre sua própria escolarização durante a Educação Básica: "No Ensino Fundamental, eu estudei na pública, mas era 
uma pública boa. Hoje mesmo eu olho para trás e vejo que lá foi a melhor escola em que estudei. A do Ensino Médio, deixou muito a desejar. Que lá [a do Ensino Fundamental] era escola do município, tinha professor para tudo e os professores eram fixos só naquela escola praticamente, então, tudo influi nisso (Laura).

Percebe-se, nessa narrativa, uma percepção de qualidade intrinsecamente ligada ao professor. Cabe salientar que a presença do professor em apenas uma escola é um dos fatores que pode contribuir para a melhoria de suas condições de trabalho e, consequentemente, do trabalho desenvolvido com os estudantes.

Nesse sentido, embora não transpareça em seus discursos a percepção da responsabilidade do poder público, transparece uma compreensão de que as condições de trabalho no Ensino Médio, em geral, não foram adequadas, o que contribui para a baixa qualidade das aulas, o que pode ser ilustrado por outro trecho mencionado por Laura sobre sua escolarização: “era bem complicado mesmo. Salas lotadas, o pessoal falava muito e era, assim, a escola era enorme, era público de vários lugares [...] aí acabava piorando, eu acredito".

Ao se referirem aos problemas enfrentados pela escola pública, embora manifestem que são muitos os defeitos, novamente centralizam a atenção no professor, dessa vez ressaltando a má formação dos professores como um dos problemas principais: “[...] os professores não tinham uma boa formação, era a engenheira que fez a licenciatura em um curso a distância. Eu acho um pouco complicado o Estado contratar esse perfil de profissional. Eu acho que começa aí. A aula não era boa, claramente essa pessoa está na escola para compor a renda de casa, mas não tem interesse ou prazer em atuar na profissão" (Guilherme, ao descrever o perfil que percebe nos professores da rede pública, relatando com base no período em que estagiou em uma escola da rede estadual).

O que consta deste excerto pode ser pensado sob diferentes ângulos. De um deles, responsabilizar apenas os docentes quanto à eventual má 
qualidade do ensino público, não apenas reduzindo o problema somente (ou principalmente) a deficiências em sua formação, mas minimizando (ou ignorando) o papel das más condições de infraestrutura das escolas e da precariedade das condições de trabalho dos professores é uma visão politicamente simplista, que tende a desresponsabilizar o poder público pelos resultados insatisfatórios que a Educação do País vem exibindo ano após ano, em quaisquer das avaliações divulgadas. Esta perspectiva centraliza o foco da atenção no indivíduo e não no contexto.

De outro ângulo, quando os licenciandos entrevistados reivindicam que a escola deva ser ocupada por pessoas com formação adequada, vão ao encontro da valorização da escola e, consequentemente, dos docentes. A ocupação do espaço escolar por pessoas alheias ao Ensino e à Educação é uma das formas mais sutis de desvalorização da profissão de professor, implicando na propagação da ideia de que o trabalho desenvolvido no ambiente escolar é passível de ser realizado por qualquer pessoa, independentemente de sua formação qualificada para isso ser insuficiente ou nenhuma (AZANHA, 1995; LIBÂNEO; OLIVEIRA; TOSCHI, 2012).

Outro prisma possível, não excludente dos demais, é a valorização de uma formação mais prestigiada no Ensino Superior (ES) público, especialmente mencionada por Laura e Tarsila. Cabe mencionar que as condições de trabalho, a formação dos docentes e a estrutura física, se comparadas as escolas do sistema básico de ensino, são distintas, embora ambas façam parte de um mesmo sistema público de ensino. Assim, embora a formação desses estudantes estivesse se realizando no sistema público, no momento das entrevistas, sua percepção está ancorada em uma perspectiva de excelência, o que é evidenciado, por exemplo, por meio da dúvida enfrentada por Tarsila ao sentir a necessidade de cursar a Licenciatura, na ocasião da conclusão do curso de Química Ambiental, nessa mesma universidade: para a jovem, a universidade em que estudou se configuraria como única alternativa com qualidade para contribuir com sua formação, "[...] bem, eu tenho duas possibilidades: volto para concluir o curso de 
Licenciatura ou faço a Licenciatura em uma faculdade particular, só para ter o diploma e tal, e não vai mudar tanto porque eu já fiz o curso de Química praticamente inteiro. Mas, aí, eu quis voltar para cá, por uma questão de qualidade das disciplinas (Tarsila).

$\mathrm{Na}$ representação dos licenciandos sobre a escola pública básica, constantemente, foi evocada uma representação sobre o sistema particular, em um movimento de comparação com o sistema público. As representações reveladas pelos estudantes trazem a marca do contexto em que estão/estiveram inseridos. Com exceção de Laura, os demais entrevistados vivenciaram esse outro sistema, seja na condição de aluno do Ensino Médio (EM), como Simone e Guilherme, ou como estagiários e, também como docentes, como esses já mencionados e Tarsila.

Por meio da vivência desses sujeitos, nessa comparação se destaca, nos fragmentos das entrevistas, uma percepção acerca das aulas desenvolvidas no ambiente público como desprovidas de planejamento e, da mesma forma, de aprendizado por parte dos estudantes. Esses trechos, destacam, ainda, que os profissionais atuantes nesses dois sistemas possuem formações distintas; além disso, a estrutura física das escolas também é diferente: "a minha experiência com escola pública é sempre muito banalizada. O professor entra, ensina qualquer coisa, de qualquer jeito. O professor acha que ensinou, o aluno acha que entendeu, assim segue a vida e ok" (Tarsila). "Olha, eu vejo que a formação dos professores que atuam nessas diferentes escolas é diferente" (Guilherme); “[...] a escola privada é divertida, além de um laboratório super legal, os professores são obrigados a serem atentos com você, com o que eles estão falando para você. $\mathrm{Na}$ escola pública, não há esse cuidado, os professores falam o que lhes vem à cabeça, eles não respeitam seu momento, sua reflexão" (Simone).

Já Laura, por sua vez, não vislumbra grandes diferenças entre os sistemas de ensino; para essa jovem, o único aspecto a distinguir esses sistemas se refere ao tratamento dos alunos para com os professores: a 
"diferença é que, na particular, vai ter um monte de aluno sendo ruim com você, porque eles acham que pagam seu salário”.

A representação social destes licenciandos quanto ao docente que atua na escola pública reflete seu meio social e, em síntese, retrata o professor atuante nesse sistema de ensino como possuidor de uma formação deficiente que conduz a uma atuação em sala de aula também de baixa qualidade. Tendo em vista que os sujeitos agem sobre a realidade pautados por suas representações sociais (ABRIC, 2001; JODELET, 2001; MOSCOVICI, 2012; WACHELKE; CAMARGO, 2007), pode-se compreender o desejo dos licenciandos em atuar ou não na rede pública de ensino, a partir da análise de suas representações sociais sobre essa instituição. Assim, enquanto Guilherme e Tarsila entendem que fazer parte desse grupo de profissionais seria como assumir a atribuição da baixa qualidade, Laura e Simone conseguem perceber outras perspectivas.

Declarando estar ciente de possíveis dificuldades, Laura anuncia o desejo de atuar como professora no âmbito público, "a gente sabe das dificuldades, mas a escola pública é o lugar de que eu gostava mais [...]. E, eu também vim de escola pública, eu também vim da periferia, então eu me sentia em casa". Esse desejo também é compartilhado por Simone, para quem o anseio de atuar na rede pública vincula-se à possibilidade de atuar de modo oposto àquele que percebeu em muitos dos docentes durante sua formação: com "o cuidado ao preparar sua aula, tomar cuidado ao enxergar seu aluno".

Por outro lado, em uma perspectiva de negação dos aspectos da identidade que eles vislumbram nos docentes da rede pública, Tarsila e Guilherme declaram não desejarem atuar na rede pública. Desejo que pode ser compreendido pelo modo como eles almejam ser reconhecidos, o que está intimamente ligado a sentimentos de valorização. Tarsila e Guilherme explicitam o quanto se espelham em professores com quem tiveram contato durante o estágio e o ES: "eu acho que os professores que eu acompanhei no meu estágio foram ótimas referências [...] Eu tento me espelhar um pouco 
nas professoras que acompanhei, em alguns professores que eu vi aqui no curso superior" (Tarsila).

A análise desse fragmento da entrevista revela a identidade visada desses sujeitos: estar em um grupo de referência mais valorizado, melhor remunerado e com melhor formação, o que está diretamente relacionado com a representação social sobre os docentes que atuam na rede privada e no ES desses licenciandos.

Compreender-se com uma boa formação também implica entender que sua possível atuação no sistema público se configuraria como uma "salvação" dos estudantes ali inseridos, "Eu penso que eu teria um papel um pouco moral. Eu vivi essa experiência, deveria fazer parte eu ter que passar por esse processo para ajudar outros alunos, tentar mudar a cabeça de outros alunos e uma série de coisas. Por mais que eu sinta um pouco essa obrigação implícita em mim, eu não acho muito justo eu estar me empenhando tanto por uma boa formação e não ter uma remuneração de acordo" (Tarsila).

O uso do verbo no futuro do pretérito, tempo verbal utilizado para indicar hipótese, incerteza e, ainda, ações que viriam a acontecer, porém não se concretizarão, demarca que essa realidade não faz parte dos planos de Tarsila e Guilherme. O que é justificado por eles pela remuneração inadequada que recebem os professores da rede pública de ensino, em especial a estadual, na qual esses estudantes poderiam atuar. Informações referentes ao estado de São Paulo indicam que o salário inicial de um professor que leciona para classes de anos finais do Ensino Fundamental e do Ensino Médio, com jornada de 40 horas semanais, seja de $\mathrm{R} \$ 2.298,80$ (SEE-SP, 2017), o que corresponderia a $\mathrm{R} \$ 10,94$ por hora/aula, à guiza de comparação com os valores praticados pela rede privada do ensino básico. Nesse sentido, reafirmamos que

a consciência da precariedade das condições de trabalho inerentes à profissão de professor no Brasil, perpassando pela decadência de sua imagem social, diagnosticadas através de inúmeros estudos, 
deve ser acompanhada [...] pela disposição em lutar pela melhoria dessas condições, em um movimento permanente de aliança entre os docentes, a sociedade e o governo, em prol da valorização da categoria (MIRANDA, 2014, p. 24).

\section{Considerações}

A partir da análise das entrevistas, foi possível depreender que o compartilhar de RS acerca de um objeto não implica, necessariamente, em modos singulares de atuação. A proposição de Dubar soma-se à de Moscovici, ao possibilitar uma interpretação de que os sujeitos podem se afetar e constituir aspectos de sua identidade profissional de modo distinto, como pode ser ilustrado no caso da RS acerca da escola pública e de seus respectivos docentes. Neste caso, os jovens compartilham uma RS do professor atuante nesse sistema de ensino como um profissional com uma formação deficiente, a qual conduz a uma atuação em sala de aula também de baixa qualidade. No entanto, agem de modo antagônico perante tal representação: enquanto uns manifestam o desejo pela atuação nesse sistema de ensino, outros não veem essa possibilidade. Atuar como professor na rede pública de ensino pode implicar, para alguns sujeitos, assumir essa atribuição de baixa qualidade, enquanto, para outros, vincula-se à possibilidade de atuar de modo oposto àquele retratado nesta RS.

Os relatos que compuseram os dados deste estudo nos auxiliam a compreender o papel do olhar do outro na constituição identitária. É por meio de tal olhar que o sujeito pode também se reconhecer. Esperamos que os estudos identitários, como o presente estudo, possam vir a contribuir para uma ressignificação da formação docente. Assim, a formação docente é reafirmada enquanto construção diacrônica, permeada pelo contexto social. 


\section{Referências}

ABRIC, J.C. O estudo experimental das representações sociais. In: JODELET, D. (Org.). As representações sociais. Rio de Janeiro: EdUERJ, 2001. p. 155-171.

AZANHA, J.M.P. Cultura Escolar Brasileira: um programa de pesquisa. Educação: Temas polêmicos. São Paulo: Martins Fontes, 1995, p. 67-78.

BARDIN, L. Análise de conteúdo. Lisboa: Edições 70, tradução L. A. Reto \& A. Pinheiro, 1977.

BOURDIEU, P. Escritos de educação. 16. ed. Petrópolis: Vozes, 2015.

; PASSERON, J-C. A reprodução: elementos para uma teoria do sistema de ensino. 6.ed. Petrópolis: Vozes, 2013.

CANDAU, V. M. Diferenças Culturais, Interculturalidade e Educação em Direitos Humanos. Educação e Sociedade, v.33, p. 235-250, 2012.

DUBAR, C. Formes identitaires et socialisation professionnelle. Revue Française de Sociologie, v. 33, n. 33-4; p. 505-529, 1992. Disponível em: http://www.persee.fr/web/revues/home/prescript/article/rfsoc_00352969_1992_num_ 33_4_5622. Acesso em: 17 jun. 2015.

A socialização: construção das identidades sociais e profissionais. São Paulo: Martins Fontes, 2005.

A crise das identidades: A interpretação de uma mutação. São Paulo: Editora da Universidade de São Paulo, 2009.

FREIRE, P. Educação como prática de liberdade. Rio de Janeiro: Paz e Terra, 1967.

. Pedagogia da autonomia. 25.ed. Rio de Janeiro: Paz e Terra, 2002.

. Pedagogia do oprimido. 44.ed. Rio de Janeiro: Paz e Terra, 2005.

JODELET, D. Representações sociais: um domínio em expansão. In: JODELET, D. (Org.). As representações sociais. Rio de Janeiro: EdUERJ, 2001. p. 17- 44.

LIBÂNEO, J. C.; OLIVEIRA, J. F.; TOSCHI, M. S. Educação escolar: políticas, estrutura e organização. $10^{\circ}$ ed. São Paulo: Cortez, 2012.

LÜDKE, M; ANDRE, M. E. D. A. Pesquisa em educação: abordagens qualitativas. São Paulo, SP: EPU, 1986.

MENDONÇA, S. G. L. A crise de sentidos e significados na escola: a contribuição do olhar sociológico. Cadernos Cedes, v. 31, n. 85, p. 341-357, 2011.

MIRANDA, C. L. As representações sociais de licenciandos em Química sobre "Ser Professor”. São Paulo, 2014. Dissertação de Mestrado - Faculdade de Educação, 
Instituto de Física, Instituto de Química e Instituto de Biociências - Universidade de São Paulo.

. As representações sociais de escola e docência e a constituição identitária de licenciandos em Química. São Paulo, 2018. Tese de doutorado - Faculdade de Educação, Instituto de Física, Instituto de Química e Instituto de Biociências Universidade de São Paulo.

., PLACCO, V. M. N. S.; REZENDE, D. B. A Teoria das Representações Sociais e a Identidade Profissional na perspectiva de Claude Dubar: contribuições para a compreensão da profissão docente In: MISSIAS-MOREIRA, R.; SALES, Z. N.; FREITAS, V. L. C.; OLIVEIRA, D. C. (Orgs.). Representações Sociais, Educação e Saúde: um enfoque multidisciplinar. 1 ed. Curitiba: CRV, 2017, v.3, p. 59-74.

., PLACCO, V. M. N. S.; REZENDE, D. B. As atribuições dos "outros significativos e dos outros generalizados" na constituição identitária de licenciandos em Química. Educação e Cultura Contemporânea, v. 15, n. 41, p. 230259, 2018.

.; PLACCO, V. M. N. S. ; REZENDE, D. B. As representações sociais de docência e a constituição identitária de licenciandos em Química. Revista Educação em Questão (Online), v. 57, n. 54, p. 1-25, 2019.

MOSCOVICI, S. Das representações coletivas às representações sociais: elementos para uma história. In: JODELET, D. (Org.). As representações sociais. Rio de Janeiro: EdUERJ, 2001. p. 45-66.

. A psicanálise, sua imagem e seu público. Petrópolis: Vozes: 2012.

Vozes, 2013.

Representações sociais: investigações em psicologia social. $10^{\circ} \mathrm{ed}$. Petrópolis:

SANTOS, W. L. P. Educação Científica Humanística em Uma Perspectiva Freireana: Resgatando a Função do Ensino de CTS. Alexandria Revista de Educação em Ciência e Tecnologia, v.1, n.1, p. 109-131, 2008.

SEE-SP. Cerca de 18,3 mil professores recebem reajuste salarial nesta terça-feira (7). Disponível em: http://www.educacao.sp.gov.br/noticias/cerca-de-18-3-milprofessores-recebem-reajuste-salarial-nesta-terca-feira-7. Acesso em 27 jun. 2017.

WACHELKE, J. F. R.; CAMARGO, B. V. Representações Sociais, Representações Individuais e Comportamento. Revista Interamericana de Psicologí/Interamerican Journal of Psychology, v. 41, n. 3, p. 379-390, 2007.

YOUNG, M. F. D. Para que servem as escolas?. Educação e Sociedade, v. 28, n. 101, p. 1287-1302, 2007.

Recebido em outubro de 2018.

Aprovado em maio de 2019. 